\title{
Using the Kostiakov - Lewis Infiltration function to evaluate a furrow irrigated field at Mhlume, a region in the north-eastern Lowveld of Eswatini (Southern Africa)
}

\author{
M. V. Dlamini
}

Department of Agricultural and Biosystems Engineering, Faculty of Agriculture, University of Eswatini, Private Bag, Luyengo, Luyengo, M205. Swaziland.

\begin{abstract}
The Eswatini sugar industry grows fully irrigated sugarcane on 57420 hectares of land producing 6197753 tonnes of cane and 871301 tonnes of sucrose annually (ESA-Integrated Report, 2019). Poor and inefficient furrow irrigation is still practiced by many growers in particular the poor small holder farmers in the industry. The two treatments were; in-row irrigated furrows and interrow irrigated furrows. A total of ten advance-recession measures were conducted, five were conducted on each treatment. The furrows were of length of $240 \mathrm{~m}$ and gradient along the furrows was 1:250. Two Washington State flumes were used to measure flow. One was used to measure inlow at the beginning of the furrow, and another one was used to measure runoff (outflow) at the end of the fourrow. The time water was allowed into the furrow was recorded. Other measurements included the time water reached the furrow end, the time to the middle of the furrow, the wetted perimeter at each point, the depth of flow and the top width of the water level. These measurements were required for the calculation of the Kostiakov exponent " $a$ " and the coefficient " $k$ ".

The results showed that the distribution uniformity (84\%), application efficiency (88\%) and deep percolation ratio $(11 \%)$ were better in interrow irrigation than in in-row irrigation. However, runoff was higher with interrow irrigation at $6 \%$ compared to $2 \%$ with in-row irrigation.
\end{abstract}

Keywords-Evaluation, infiltration, application efficiency, deep percolation, run-off, Kostiakov-Lewis function.

\section{INTRODUCTION}

Furrow irrigation is probably the oldest and most widely used method for applying irrigation water to many field crops and vegetables worldwide (Walker and Skogerboe, 1989; Nie et al., 2018). At Mhlume the irrigation of sugarcane using furrow irrigation covers 6072 hectares which is $66 \%$ of the area under sugarcane. This method uses the furrow for the control of water after it leaves the head - ditch or step-canal. On land that has not been properly leveled or graded relatively smaller streams of water should be used in the furrow to prevent erosion and loss of water by runoff at the end of the rows. Where the land has been leveled and well prepared, larger streams can be used without fear of erosion or loss of water at the end of rows. Balancing the inflow, the application uniformity, deep percolation losses and tailwater runoff are the many challenges of using furrow irrigation to most farmers.

Measured furrow flow rates at Mhlume ranged from 1.0 litres per second to a maximum of 7.0 litres per second depending on the method of head control, soil type and furrow length. Under certain conditions of tillage where the water flow velocity in the furrow is retarded by cloddiness or vegetation (trash, weeds etc.), larger amounts of water per furrow can be used without damage to the crop or causing excessive erosion in the furrow.

If the individual furrow streams are too small, too much time will be required for the advancing water front to reach the end of the furrow and the soil near the head ditch or stepcanal (to approximately $50 \%$ of the furrow length) will be over - irrigated before the lower end has been wetted 
sufficiently. In furrow irrigation, the most important criteria therefore are to adequately select furrow irrigation variables (furrow length, time of cut-off, and discharge), improve irrigation scheduling, and improve water management of the field which will also potentially reduce over-irrigation and deep percolation of applied water (Holzapfel et al., 2010).

The factors that affect the performance of an irrigation method are; rate of infiltration of water into the soil; inflow rate of the water; slope of the field; time of irrigation; time of recession of water from the soil surface; soil moisture prior to irrigation; spatial variability of the soil; climatic conditions; and furrow shape (Walker, 2003; Walker and Skogerboe, 1987 ; Hsiao et al., 2007)..

The field evaluation of a surface irrigation system helped to identify modifications that enhanced the hydraulic performance. Besides the easily identified problems of applying too much or too little water onto the soil, the distribution of infiltrated water over the field may vary considerably, tail water runoff may be excessive, or significant deep percolation losses may occur. Solutions to these problems are numerous. In fact, the optimal solution is usually a combination of several remedies (Walker, 2003). When discussing changes in discharge, time of cut off, slope and length of run, any alteration in one of these parameters will affect one, or more of the other parameters. Methods of evaluation differ depending on the available resources and the experience of the researcher.

The Kostiakov - Lewis equation below is one of the simplest used for furrow evaluation (Walker and Skoggerboe (1987), (Xanthoulis and Wallender (1991); Childs et al., (1993)).

$$
\mathrm{Z}=\mathrm{k} \mathrm{T}^{\mathrm{a}}+\mathrm{f}_{\mathrm{o}} \mathrm{T}
$$

where;

$$
\begin{aligned}
& Z=\text { infiltrated volume per unit } \\
& \text { length }\left(\mathrm{m}^{3} / \mathrm{m}\right) \text {, } \\
& T=\text { opportunity time ( } \mathrm{min}), \\
& \mathrm{a}=\text { Kostiakov exponent, } \\
& k=\text { Kostiakov coefficient and } \\
& \mathrm{f}_{\mathrm{o}}=\text { the steady or basic } \\
& \text { infiltration rate }\left(\mathrm{m}^{3} / \mathrm{m} / \mathrm{min}\right) \text {. }
\end{aligned}
$$

The advantage of the Kostiakov - Lewis function is that it makes use of the volume balance approach, meaning that all the parameters are measured in the field and secondly predictions could be made as to the effect of changing some of the parameters on the performance of irrigation.

\section{MATERIALS AND METHODS}

A total of ten advance-recession measurements were conducted, five were on in-row irrigated furrows and the other five were on interrow irrigated furrows. Furrows were parabolic in shape with a standard spacing of $1.5 \mathrm{~m}$. The gradient along the furrow was 1:250. Each furrow had an approximate top width ranging from $0.6 \mathrm{~m}-0.8 \mathrm{~m}$ and a water flow depth of $0.08 \mathrm{~m}$ to $0.15 \mathrm{~m}$. The soils were relatively of moderate infiltration.

The advance - recession set up consisted of two Washington State flumes (WSC), one placed five metres from the stepcanal used for measuring inflow and the other placed at the end of the furrow, used for measuring runoff (outflow). Water was introduced into the furrows and the advance distances and time of reaching each stake were measured (Issaka et al., 2015; Walker, 2003). It was essential to ensure that inflow did not vary with time. The type of field selected for the measurement was one with a neyrpic gate and a stepcaral that is fitted with duckbill weirs.

Wooden stacks were placed $30 \mathrm{~m}$ apart (figure 1) along the entire furrow. The time water was allowed into the furrow was noted. The movement of the advance was noted by recording the time water arrive at each woodstack (station). This was done until the water had reached $80 \%$ of the furrow length as per estate practice before cutting off the inflow from the stepcanal. Recession (time) was taken as the time when the tail of water passed a woodstack. A degree of subjective judgement is required for recession, but errors are small in magnitude when compared to the contact time.

Other measurements included the time water reached the furrow end $T_{L}$, the time to the middle of the furrow $T_{1 / 2 L}$, the wetted perimeter at each point (wp), the depth of flow (y) and the top width of the water level (T) at each station along the furrow. These measurements were required for the calculation of the Kostiakov exponent "a" and the coefficient " $k$ " as described by Walker and Skoggerboe (1987).

The steady or basic infiltration rate $f_{o}$ was measured on another set of furrows by using the inflow -outflow method. Figure 1 below shows the position of the measuring points in relation to the stepcaral. 


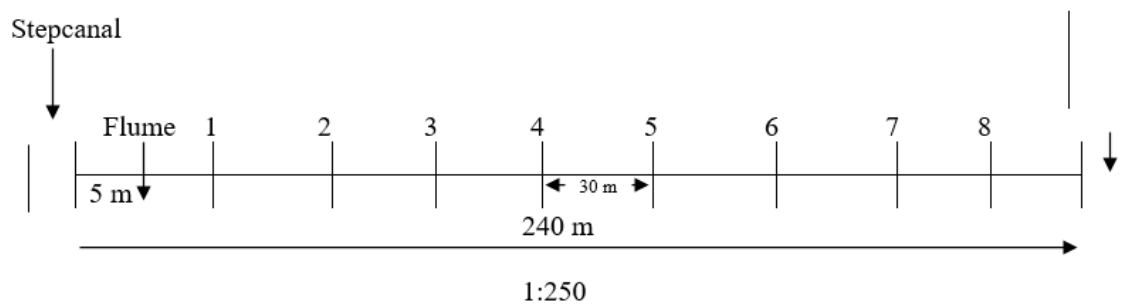

Fig.1: Schematic diagram showing the position of the WSC flume and measuring points along the furrow.

\section{RESULTS AND DISCUSSION}

The field measurement techniques provided the means for defining the following six important elements in the evaluation; the inflow discharge, the advance and recession of the water over the field surface, the tail water discharge, the soil moisture after the irrigation, the volume of water on the soil surface at various times, and an indication of the subsurface infiltration characteristics of water on the soil.

\section{Inflow-outflow hydrographs}

Figure 2 and figure 3 show the inflow - runoff hydrograph for the inter-row irrigation event and the in-row irrigation events respectively. The area under each graph gives the total volume of water applied and the total volume of runoff. The volume of water applied in the in-row situation was $37.6 \mathrm{~m}^{3}$ compared to $24.2 \mathrm{~m}^{3}$ in the inter-row event which was $55 \%$ higher. The total volume which occurred as runoff was however, higher in the inter-row situation $5.5 \%$ than in the in-row situation which was $2.3 \%$.

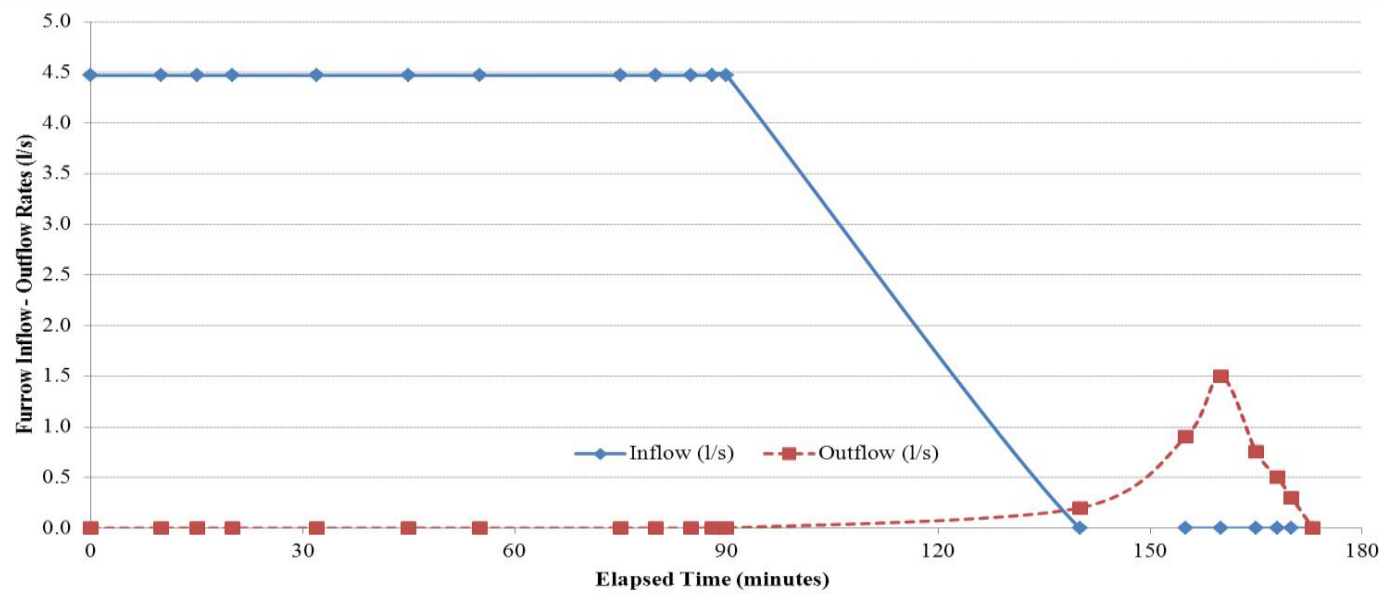

Fig.2: The graph showing the inflow-runoff hydrograph for the inter-row irrigation events.

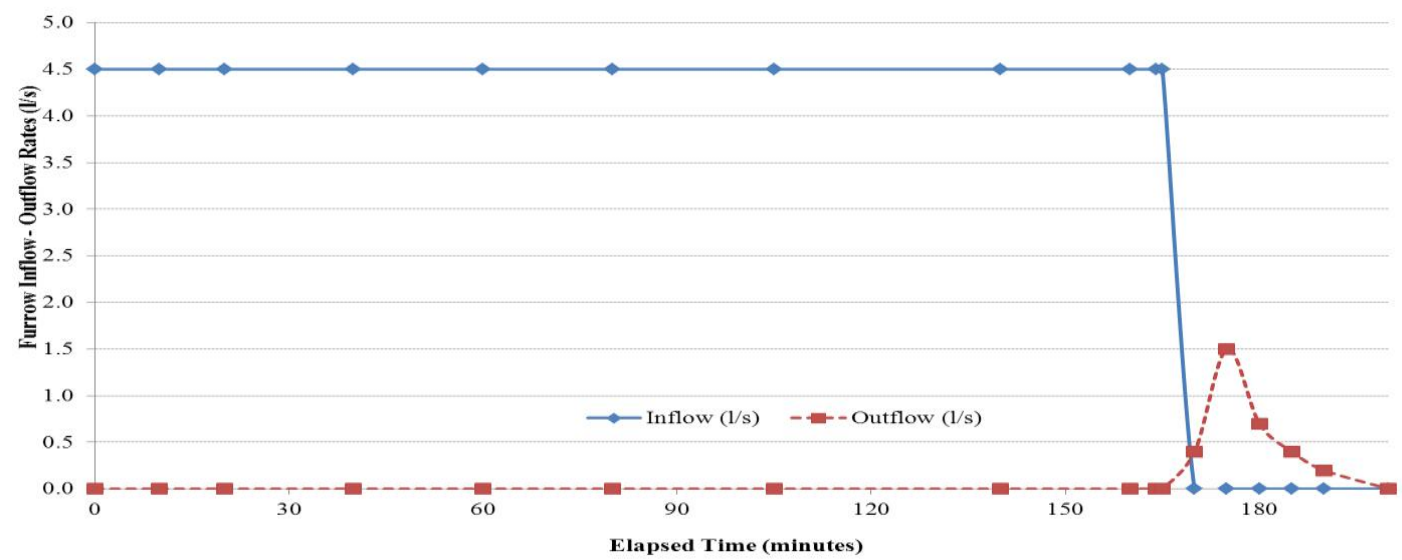

Fig.3: The graph showing the inflow-runoff hydrograph for the in-row irrigation events 
Water reached the cutoff point in about 90 minutes in the inter-row irrigation compared to about 160 minutes in the in-row irrigation event. The sugarcane growing along the furrow in the case of the in-row irrigation event provided resistance to the advancing front.

\section{Subsurface distribution of water along the furrows}

The subsurface distribution of water along the furrow is shown in figure 4 . The depth of water applied in the in- row irrigation event was greater than that applied in the inter-row irrigation case. This was due to the resistance to water flow by the cane resulting in a higher opportunity time per unit length of furrow in the in-row event. Water flow was faster in inter-row irrigation resulting in less opportunity time.

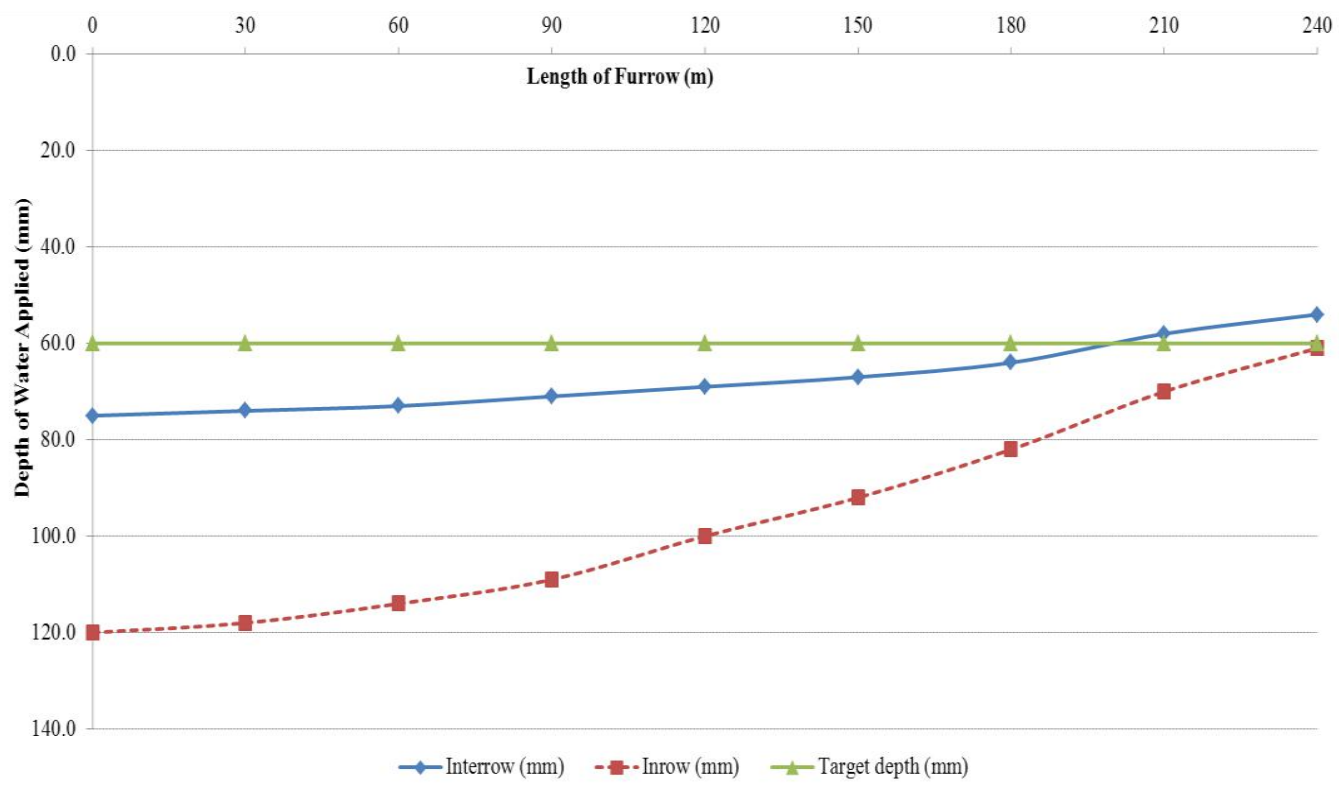

Fig.4: The subsurface distribution of water along the measured furrows.

The results showed that the target amount of $60 \mathrm{~mm}$ per furrow was highly exceeded in the inrow irrigation event compared to the interrow irrigation event, with the later under applying the last $30 \mathrm{~m}$ of the furrow.

The analysis of the field data allowed for the quantitative definition of the irrigation system performance. Such performance reflects, of course, not only the physical features of the system but its management as well. Occasionally, the inflow is cut off shortly after completion of the advance phase, and the application at some point in the field is inadequate to meet the requirements. At other times, the requirements are met with the least watered areas just receiving the required amount of water. Finally, and most often, the applied depths exceed the requirement at all locations. Because of the large differences in economic, physical, social and operational conditions that occurred in surface irrigation, it is impossible to place quantitative judgement on any of these cases.

The measures for the irrigation performance for the inrow and interrow irrigations are summarized in table 1.

Table 1. Measures of Irrigation performance for Interrow and In-row irrigation

\begin{tabular}{|c|c|c|}
\cline { 2 - 3 } \multicolumn{1}{c|}{} & INTERROW IRRIGATION & IN-ROW IRRIGATION \\
\hline Distribution uniformity & $84 \%$ & $67 \%$ \\
Application Efficiency (Ea). & $88 \%$ & $48 \%$ \\
Deep Percolation Ratio (DPR) & $11 \%$ & $27 \%$ \\
Run off $(\boldsymbol{\%})$ & $6 \%$ & $2 \%$ \\
\hline
\end{tabular}


The application efficiency for in-row irrigation was low at $48.1 \%$ and had a high deep percolation ratio of $26.8 \%$. This indicated that $27 \%$ of the water applied on the furrow was lost due to deep percolation. The deep percolation was being measured against the targeted application depth. In furrow irrigation, deep percolation losses are usually unknown by most managers and because they are hidden, irrigators tend to be praised for no-runoff yet deep percolation is enormous.

\section{DISCUSSION}

The challenge in furrow irrigation is to predict the required opportunity time to enable the irrigator to apply the correct amount of water. The Newton - Raphson method was used to predict the required opportunity time to apply the target $60 \mathrm{~mm}$ for each irrigation event. The assumption was that no change was to be made on the furrow length, width (shape) and inflow volume. This resulted in the following times (Table 2).

Table 2: Comparison of the actual times and the calculated times for each irrigation event

\begin{tabular}{|c|c|c|c|c|}
\cline { 2 - 5 } \multicolumn{1}{c|}{} & \multicolumn{2}{c|}{ INTERROW } & Actual & Calculated \\
\cline { 2 - 5 } & Actual & Calculated & $53<\mathrm{x}<166$ & $50.9 \mathrm{~min}$ \\
\hline Opportunity time (range) & $51<\mathrm{x}<91$ & $92.8 \mathrm{~min}$ & $166 \mathrm{~min}$ & $174.2 \mathrm{~min}$ \\
\hline Time of Advance $\left(T_{L}\right)$ & $91 \mathrm{~min}$ & $33.7 \mathrm{~min}$ & $61 \mathrm{~min}$ & $62.7 \mathrm{~min}$ \\
\hline Time of Advance $\left(T_{1 / 2 L}\right)$ & $33 \mathrm{~min}$ & & & \\
\hline
\end{tabular}

Where: $T_{L}$ - time (minutes) of advance to the full length of furrow.

$T_{1 / 2 L}$ - time (minutes) of advance to the middle of the furrow.

The implication of these results is that the water must spend $36 \%$ of the time from the inlet to the middle of the furrow and the rest $64 \%$ to the end of the line in order to minimise deep percolation and runoff while ensuring uniform application.

\section{Application of the results for management decisions}

The outcome of the evaluations had the following design implications; since both the distance (length of the furrow) and the time (required opportunity time to apply a certain depth of water) are known, then the water flow velocity can be calculated. Using Manning's equation $V=k R^{2 / 3}$ $S^{I / 2}$, where $k=1 / n$, and $R$ the hydraulic radius measured for a given furrow, the slope $S$ can be calculated for maximum efficiency. This resulted in the adoption of the use of compound slopes which is now a practice at Mhlume.

Where in many cases the slope is limiting, one has to vary the water inflow into the furrow. A simple relationship (Equation 2) was developed based on the above analysis, which states that the furrow inflow $q$ is proportional to the depth of water to apply per unit time and the total furrow area, i.e.

$$
q=k^{*} C^{*} A
$$

where;

$k$ - is a proportionality constant incorporating time(s) $=\left(2.78 \times 10^{-4}\right)$.
$C$ - gross depth of water applied (mm)

$A$ - is the furrow area defined as length by spacing $\left(\mathrm{m}^{2}\right)$

For example, for a $50 \mathrm{~mm}$ depth, the derived $q$ and $L$ values are summarized in table 3 :

Table 3: Derived furrow inflow $(l / s)$ for a given furrow length $(m)$

\begin{tabular}{|c|c|}
\hline Furrow length $(\mathrm{m})$ & $\begin{array}{c}\text { Furrow inflow } \\
(\mathrm{l} / \mathrm{s})\end{array}$ \\
\hline 50 & 1.04 \\
100 & 2.09 \\
150 & 3.13 \\
200 & 4.17 \\
250 & 5.21 \\
300 & 6.26 \\
\hline
\end{tabular}

\section{CONCLUSION}

The Kostiakov - Lewis function was successfully used for the evaluation of two types of furrow irrigation system performances at Mhlume. It has the advantage of providing analytical solutions to the flow equations which could easily be solved. The fact that all the parameters used in the equations were based on actual measurements 
on the field being evaluated, the results and predictions could be trusted and considered accurate. The measurement of advance rates, hydraulic cross-sections, and tailwater volumes provided the basis for any furrow irrigation evaluation.

It is clear that in-row irrigation cannot be favoured where the length of the furrow is more than $100 \mathrm{~m}$. Deep percolation losses are higher in in-row irrigation than in interrow irrigation. The effect of water losses by surface runoff is not as serious as compared to deep percolation provided sound management practices such as cutback, reuse and the quarter time rule are practiced.

A simple relationship of inflow and furrow length was developed to guide engineers and managers on the approximate flow rate for a given length of furrow. Such measurements are field specific as they are dependent on the soil type.

Multitude furrow slopes would help reduce deep percolation and improve water application efficiency in furrow irrigated fields.

\section{REFERENCES}

[1] Bautista, E. and Wallender, W.W. (1985). Spatial variability of infiltration in furrows. Trans. ASAE 1985, 28 , 1846-1851.

[2] Childs, J.L., Wallender, W.W., Hopman, J.W., 1993. Spatial and seasonal variation of furrow infiltration. J Irrig. Drainage Eng. ASCE 119 (1), 74-90.

[3] ESA-Integrated Report. (2019). Integrated Annual Report 2018/19. Pages: 1 - 52

[4] Eduardo A. Holzapfel1, Carlos Leiva1, Miguel A. Mariño2, Jerónimo Paredes1, José L. Arumí1, and Max Billib3 (2010). Furrow Irrigation Management and Design Criteria Using Efficiency Parameters and Simulation Models. CHIL. J. AGRIC. RES. 70(2):287-296

[5] Hsiao, T., P. Steduto, and E. Fereres. (2007). A systematic and quantitative approach to improve water use efficiency in agriculture. Irrig. Sci. 25:209-231.

[6] Issaka, R. Z., Ibrahim. H., Issah, M.H. (2015). Performance Evaluation of Furrow Lengths And Field Application Techniques. International Journal of Scientific \& Technology Research Volume 4, Issue 10, October 2015, 278 - 281. ISSN 2277-8616.

[7] Izadi, B., King, B., Ashraf, M.S., Evaluation of the portable furrow infiltrometer. Agricultural water management (34), 1977, 207-205.

[8] Nie, Wei-Bo, Yi-Bo Li, Fan Zhang, Shu-Xin Dong, Heng Wang and Xiao-Yi Ma, (2018). A Method for Determining the Discharge of Closed-End Furrow Irrigation Based on the Representative Value of Manning's Roughness and Field Mean Infiltration Parameters Estimated Using the PTF at Regional Scale. Water 2018, 10, 1825; doi:10.3390/w10121825
[9] Walker, W.R., 1989. Guidelines for designing and evaluating surface irrigation systems. FAO Irrigation and Drainage paper (45)

[10] Walker, W.R., Skogerboe, G.V., 1987. Surface irrigation theory and practice. Prentice - Hall, Englewood Cliffs. NJ. 